\title{
MUDANÇAS NO PADRÃO BRASILEIRO DE FINANCIAMENTO À INFRAESTRUTURA E SUAS IMPLICAÇÕES TERRITORIAIS
}

\author{
Bruno Moreira Riani Costa ${ }^{1}$
}

Resumo: No presente trabalho são sumarizados processos atualmente em curso no Brasil e que apontam para uma modificação das bases do financiamento à sua infraestrutura territorial. Em primeiro lugar, tem havido sensível crescimento do mercado de títulos privado de longo prazo, movimento entendido aqui como um efeito retardatário da mundialização financeira e das recentes políticas de estímulo ao segmento. Por outro lado, está em curso um desmonte dos meios de financiamento público à infraestrutura, que se dá principalmente via BNDES, pivô do padrão usual de financiamento à longo prazo no país. Sustentamos que estes dois movimentos não pressupõem um ao outro, de modo que o mercado de capitais poderia ser amadurecido e sofisticado sem que houvesse concomitante corrosão do sistema de financiamento público. Ainda que independentes, ambos os processos concorrem para uma maior dependência de agentes financeiros privados, implicando em novos usos do território.

Palavras-chave: BNDES; usos do território; financeirização; infraestrutura; planejamento territorial.

\section{CHANGES IN BRAZILIAN INFRASTRUCTURE FINANCING PATTERN AND ITS TERRITORIAL IMPLICATIONS}

\begin{abstract}
This work summarizes processes currently underway in Brazil that point to a change in the basis of financing for its territorial infrastructure. First, there has been a significant growth in the long-term private bond primary market, a movement understood here as a late effect of financial globalization and the recent policies to stimulate the segment. On the other hand, a dismantling of public means of financing infrastructure is underway, which takes place mainly via BNDES, the pivot of the usual long-term financing pattern in the country. We maintain that these two movements do not presuppose each other, so that the capital market could be mature and sophisticated without there being a concomitant corrosion of the public financing system. Although independent, both processes contribute to a greater dependence on private financial agents, implying new uses for the territory.
\end{abstract}

Keywords: BNDES; Brazilian territory; financialization; Brazilian infrastructure; territorial planning.

\footnotetext{
${ }^{1}$ Mestrando do Programa de Pós-Graduação em Geografia da Unesp - Rio Claro e membro do Laboratório de Investigações Geográficas sobre os Usos do Território da Unesp de Rio Claro (LUTe). E-mail: bruno.riani@ unesp.br.
} 


\section{INTRODUÇÃO}

Em uma primeira aproximação, um sistema financeiro nacional genérico (ou sistema de crédito tomado em sentido amplo, incluindo os bancos assim como as Bolsas) pode ser compreendido como o circuito através do qual flui parcela da riqueza acumulada sob forma monetária, conectando a poupança dos agentes superavitários aos demandadores de empréstimos (para consumo final ou ampliação da capacidade produtiva) e permitindo o direcionamento do capital monetário ocioso de um dado setor da economia para outro (i. e. permite uma transposição setorial) (CASTRO; LESSA, 1973). Isto posto, um papel importante que o sistema financeiro cumpre na economia capitalista é permitir o "ganho de tempo" (SINGER, 2000, p. 29): uma unidade produtiva não precisa previamente acumular um montante de recursos equivalente ao investimento que deseja realizar - fosse assim, grandes investimentos em capital fixo seriam em grande medida inviabilizados ${ }^{2}-$, mas simplesmente contratar empréstimos. Afinal, é o sistema financeiro que permite ao capital apresentar-se de forma "livre e líquida e, ao mesmo tempo, crescentemente centralizada. Apenas desta maneira pode fluir sem obstáculos para colher novas oportunidades de lucro" (BELLUZZO, 2013, p. 88) ${ }^{3}$.

Entretanto, além destas funções de concentração e intermediação - e acoplada a elas - há um outro papel intrínseco desempenhado pelos sistemas financeiros em todas as economias capitalistas: permitir a valorização do capital no próprio circuito financeiro (TAVARES, 1985, p. 109). Através deste circuito o dinheiro transforma-se em um capital que, sob forma monetária, pode valorizar-se permanecendo externo ao processo produtivo propriamente dito (CHESNAIS, 2010; HARVEY, 2013). Mais precisamente, esta valorização decorre da remuneração pelo empréstimo do capital-dinheiro (tornando-se capital portador de juro) e/ou da detenção de títulos de propriedade, que dão direito a parcela do potencial mais-valor futuro extraído da companhia da qual se detém o título (presentificando um presumido maisvalor futuro e conformando assim o chamado capital fictício) (PALLUDETO; ROSSI, 2018).

Assim, por mais que dele não participe diretamente, o capital financeiro não está completamente descolado do circuito real da extração de mais-valor e, em última instância, dele depende (BELLUZZO, 2013). Não haveria de ser diferente: como colocado por Marx (1985, p. 43, grifos nossos), "O capital industrial é o único modo de existência do capital em que não só a apropriação de mais-valia, ou, respectivamente, mais-produto, mas, ao mesmo tempo, também sua criação é função do capital." Assim sendo, o capital financeiro, ao permanecer externo ao processo produtivo, obtém sua remuneração através da apropriação de mais-valor criado na esfera da produção propriamente dita.

Isto posto, podemos pensar nos termos de um duplo caráter da finança: ao mesmo tempo em que viabiliza e permite a alavancagem do desenvolvimento capitalista (através das mencionadas funções de centralização e intermediação dos excedentes), remunera-se de forma potencialmente parasitária ao apropriar parcelas do mais-valor gerado na esfera produtiva (através da função de valorizar o capital no

\footnotetext{
${ }^{2}$ Neste sentido, como colocado por Marx (2013,p. 703): “O mundo ainda careceria de ferrovias se tivesse de ter esperado até que a acumulação possibilitasse a alguns capitais individuais a construção de uma estrada de ferro. Mas a centralização, por meio das sociedades por ações, concluiu essas construções num piscar de olhos."

${ }^{3}$ Sobre a função de centralização desempenhada pelos sistema de crédito como complementar à de intermediação, recorremos mais uma vez a Marx (1986, p. 303-304): "Pequenas somas, cada uma por si incapaz de atuar como capital monetário, são unificadas em grandes massas e constituem assim um poder monetário. Essa reunião de pequenas somas, como efeito particular do sistema bancário, deve ser distinguida de sua mediação entre os capitalistas monetários propriamente ditos e os mutuários."
} 
circuito financeiro). Conquanto estas funções sejam indissociáveis — isto é: a finança só se remunera porque financia algo e só financia algo porque ao fazê-lo se remunera -, entendemos que é possível estimar sua função predominante em dada circunstância ao avaliar a forma como se relaciona com o restante da economia e sociedade. Exemplificado com termos próximos ao recorte deste trabalho: a finança tem sido mobilizada de modo a custear o investimento em infraestrutura pública de que o Brasil demanda? Ou são os ativos em infraestrutura que têm se transformado em substrato e justificativa para uma valorização do capital no circuito financeiro? ${ }^{4}$ Dito de maneira simplificada: há financiamento para a infraestrutura ou há infraestrutura para a finança?

\section{O FINANCIAMENTO VIA MERCADO DE CAPITAIS}

A hipótese aqui é a de que os projetos de infraestrutura têm sido crescentemente financiados por fundos financeiros via mercado de capitais (através de emissão de debêntures, principalmente). Esta mudança projeta uma espécie de novo padrão porque tem sucedido à forma tradicional de financiamento à infraestrutura no país, grandemente baseada nas linhas de crédito bancário, em especial de bancos públicos, e principalmente do Banco Nacional de Desenvolvimento Econômico e Social (BNDES). Isto ocorre porque o desenvolvimento do mercado de capitais, assim como o crescente interesse de investidores institucionais no setor de infraestrutura, tem se dado de modo concomitante ao esvaziamento da função do BNDES. Neste sentido, o aqui suposto novo padrão não representa apenas a adição de uma nova forma de financiamento (mercado de capitais) à tradicional (crédito bancário via BNDES) — o que poderia ser visto como um movimento virtuoso -, mas a substituição desta por aquela.

Desde já cabe precisar a distinção entre mercado de crédito e mercado de capitais. Para tanto, valemo-nos das definições adotadas pela Comissão de Valores Mobiliários (2014), que são compatíveis com as leituras sobre o tema feitas pelos autores citados ao longo da seção. Neste sentido, o principal fator que demarca estas diferentes formas de financiamento é o grau de intermediação: no mercado de crédito a instituição financeira (em geral bancos) capta dos agentes superavitários (ou cria moeda escritural, no caso dos bancos) e concede aos tomadores, assumindo todos os riscos da operação; neste quadro, a remuneração destas instituições deriva do spread: a diferença entre o preço de captação (no caso, juros pagos ao agente que aloca seu recurso na instituição financeira) e o custo previsto na contratação do empréstimo (juros a serem pagos à instituição financeira pelo tomador). No mercado de capitais, por outro lado, a relação entre emprestadores e tomadores é direta: estes emprestam daqueles conforme termos acordados mutuamente. Aqui também há mediação, mas apenas na prestação de serviços acessórios (assessoria, consultoria, estruturação das operações etc.).

Dentro do mercado de capitais há ainda outra distinção que pode ser feita. Os títulos negociados podem ser de dívida ou de patrimônio. Os títulos patrimoniais correspondem principalmente às ações; nesta forma de operação, o investidor tornase sócio da empresa de que detém o título patrimonial, na maior parte das vezes adquirindo direito a parcela de seus rendimentos futuros. Já os títulos de dívida correspondem apenas a uma relação débito-crédito entre as partes envolvidas: os

\footnotetext{
${ }^{4}$ Em trabalho anterior, ao qual remetemos o leitor interessado, tratamos sobre o que entendemos ser uma forma (dentre outras possíveis, portanto) através da qual um ativo em infraestrutura pode tornar-se essencialmente uma plataforma para ganhos financeiros (COSTA; GALLO, 2020).
} 
tomadores comprometem-se a saldar a dívida contraída devolvendo ao emprestador o valor do principal acrescido de juros em um prazo estipulado. Uma forma tradicional de operação com títulos de dívida é a debênture: a empresa demandadora de empréstimo lança no mercado de capitais estes título com os termos definidos (duração que pode ter curto, médio ou longo prazo e taxa de juros que podem ser fixas ou variáveis, indexadas ou não) e que podem ser adquiridos por agentes superavitários interessados em ter seu capital-dinheiro remunerado nos termos propostos.

De maneira esquemática, podemos pensar que uma unidade produtiva (uma empresa, por exemplo) tem algumas formas principais de financiar suas atividades e expansões (investimentos em modernização e/ou ampliação de sua capacidade produtiva, por exemplo) a partir de fontes externas.

Aqui, vale dizer, trata-se de fontes externas à unidade produtiva, e não necessariamente externa ao país em que se encontra (ainda que o financiamento estrangeiro propriamente dito também possa ser tomado como uma categoria à parte. Neste caso, em geral se trata de emissões feitas em mercados de outros países). Essa demarcação é importante porque, no Brasil, a principal forma de financiamento das empresas é através de lucros retidos, uma forma de autofinanciamento que, portanto, não envolve captação em mercado de capitais ou de crédito (TORRES FILHO; MACAHYBA, 2012).

Feita essa ressalva, voltemos às formas de obtenção de recursos externos à empresa, que têm lugar sempre que a unidade produtiva não possui recursos próprios para financiar o investimento que almeja realizar. Há a possibilidade de contratação de crédito junto a um banco (uma operação no mercado de crédito); de listagem de ações da empresa em bolsa de valores, obtendo crédito às custas de parte do patrimônio da corporação, que passa a ser dos compradores das ações (uma operação envolvendo título patrimonial em mercado de capitais); e de captação de crédito mediante emissão de debênture (uma operação envolvendo títulos de dívida em mercado de capitais).

Ao longo do século XX os países capitalistas centrais constituíram sistemas funcionais de financiamento privado calcados ou no crédito bancário (caso de Japão e da Europa) ou no mercado de capitais (caso dos Estados Unidos). Ao longo do último quartel do século passado, entretanto, têm lugar um processo de diluição das fronteiras que demarcariam estes dois padrões distintos: há os processos de desintermediação, descompartimentalização e desregulamentação que tornam a finança mundializada (CHESNAIS, 2005) e concedem cada vez mais centralidade aos investidores institucionais; há um novo padrão sistêmico de acumulação (BRAGA, 1993) que incide diretamente sobre as formas predominantes de financiamento corporativo.

Neste sentido, conforme colocado por Coutinho e Belluzzo (1996, p. 131): "Diferentemente do que ocorreu no pós-guerra até o início dos anos 80 , a transformação das poupanças em créditos bancários cedeu lugar à finança direta, mobilizada através dos mercados dos ativos." Um padrão de financiamento corporativo centralizado no mercado de capitais, antes particularidade dos Estados Unidos, toma corpo também em outras partes do globo. ${ }^{5}$ Primeiro, no restante do centro da economia-mundo: Japão e Europa ocidental. Em seguida, e de maneira

\footnotetext{
5 “O processo de liberalização pós-1980 impulsionou o mercado americano de títulos de dívida corporativa, criando condições para seu alargamento e aprofundamento. Entretanto, o impacto da globalização financeira em outras regiões fez com que o crescimento desse tipo de emissão no resto do mundo fosse ainda mais rápido.” (TORRES FILHO; MACAHYBA, 2012, p. 10)
} 
heterogênea e diferencial, sobre os países do terceiro mundo: países asiáticos, além de México, Colômbia e Chile, lograram constituir mercados robustos e sólidos de títulos corporativos de longo prazo, diferentemente do Brasil, como se verá adiante (TORRES FILHO; MACAHYBA, 2012, p. 64).

$\mathrm{E}$ aqui, retomando a distinção feita nos parágrafos precedentes, vale dizer que, dentre os segmentos do mercado de capitais, são os títulos de dívida corporativa de longo prazo (debêntures de longo prazo) os instrumentos mais adequados ao financiamento da infraestrutura. Assim, ao longo da seção, ao reportarmo-nos ao financiamento de longo prazo (em especial de infraestrutura) via mercado de capitais, pensamos em primeiro lugar no mercado de títulos de dívida privada/debêntures de longo prazo. Neste sentido, é pertinente destacar o caráter desigual do mercado de capitais brasileiro: enquanto o mercado de ações e o de títulos de dívida pública são relativamente profundos e sofisticados, o mercado de títulos de dívida privada tem apenas muito recentemente experimentado um crescimento (TORRES FILHO; COSTA, 2013; TORRES FILHO; MACAHYBA, 2012).

Conforme coloca Costa (2015, p. 26), a origem deste atraso do desenvolvimento de um mercado de dívida privada profundo e capaz de financiar no longo prazo derivou da alta instabilidade monetária do país, que tem lugar mesmo depois de alcançada a estabilidade dos preços. Neste sentido. as altíssimas e voláteis taxas de juros, assim como taxas de câmbio também voláteis, poderiam ser apontadas como os principais obstáculos à constituição de um mercado privado de financiamento em longo prazo na década de 1990. Vale dizer, ainda seguindo Costa (2015, p. 26), que "esta instabilidade foi agravada por uma política monetária de corte stop-and-go que privilegiou a estabilização inflacionária, inclusive interrompendo ciclos de retomada de crescimento econômico".

Nos anos 2000 há diminuição da vulnerabilidade externa e consequente mitigação das vulnerabilidades monetária e cambial. É nesta década, principalmente a partir de 2004, em que há grande evolução, crescimento e modernização do mercado financeiro brasileiro, mas com desenvolvimento limitado do setor de títulos corporativos (diferentemente dos segmentos de dívida pública e o mercado de ações, como já dito, que logram se sofisticar) (TORRES FILHO; COSTA, 2013, p. 36). Neste sentido, a principal causa desta incipiência deste segmento pode ser atribuída às elevadas taxas de juros e a certos vícios do mercado financeiro nacional que faz com que os títulos de longo prazo se apresentem como pouco atrativos frente às demais aplicações (TORRES FILHO; MACAHYBA, 2012).

Ao longo da década de 2010 há introdução de inovações e propostas para estimular o amadurecimento do mercado de títulos corporativos no Brasil. Mais do que isso, a queda continuada dos patamares da taxa básica de juros (e consequentemente da remuneração dos títulos públicos), impeliu (como ainda tem impelido) investidores a buscar aplicações alternativas (TORRES FILHO; MACAHYBA, 2012). Neste sentido, estudos tem indicado um crescimento deste mercado nos últimos anos (CVM, 2018). Assim, tem crescido o interesse dos investidores institucionais no ramo da infraestrutura como forma de diversificação de portfólio frente à queda de remuneração das aplicações convencionais (títulos públicos de renda fixa, principalmente) (TAUHATA, 2020b).

Conforme dados divulgados pela Anbima (TAUHATA, 2020a), em 2019 a oferta de valores mobiliários de empresas brasileiras nos mercados financeiros, tanto doméstico quanto estrangeiro, bateram recorde na série histórica, chegando a $R \$ 498$ bilhões naquele ano contra os $\mathrm{R} \$ 300$ bilhões do ano anterior. 
Em relação às emissões de debêntures (que, como dito, aqui nos interessa em específico por ser o principal instrumento de financiamento via mercado de dívida privada), estas "mantiveram o perfil de crescimento anual que vem ocorrendo desde 2017 , com aumento do volume emitido, de $R \$ 153,7$ bilhões, em 2018, para $R \$ 173,6$ bilhões [em 2019]" (ANBIMA, 2020). À título de comparação vale dizer que, ao longo da primeira década dos anos 2000 , o ano de maior valor total emitido no mercado de debêntures brasileiro não alcança os $R \$ 40$ bilhões, conforme dados também divulgados pela Anbima e compilados por Bragança, Pessoa e Souza (2015).

Visando estimular uma maior participação dos agentes financeiros no financiamento de longo prazo, foi promulgada em 2011 a Lei 12.431. Dentre seus principais pontos destaca-se a diminuição da alíquota ${ }^{6}$ de tributos incidentes sobre rendimentos auferidos em debêntures emitidas por Sociedade de Propósito Específico atuante na área de infraestrutura (FERREIRA, 2015, p. 18). Ou seja: pessoas físicas e fundos de investimento teriam incentivos fiscais para aplicar seus recursos na compra de debêntures de companhias atuantes em projetos de infraestrutura. Isto posto, vale frisar que estas assim chamadas debêntures incentivadas de infraestrutura têm crescido em importância como meio de financiamento nos últimos anos: em 2019 foram emitidos $R \$ 33,76$ bilhões em papéis nessa modalidade; um crescimento de $56,2 \%$ em relação aos $R \$ 23,89$ emitidos no ano anterior (BRASIL, 2020a).

$\mathrm{Na}$ esteira deste movimento, foi proposto novo Projeto de Lei (2646/2020) com a finalidade de estimular este mercado: ainda em tramitação, o Projeto propõe a criação de nova debênture para investimentos em infraestrutura. Diferentemente da primeira Lei mencionada, em que os incentivos se restringem aos investidores, neste projeto as Sociedades de Propósito Específico e demais companhias atuantes no segmento também receberiam incentivos fiscais ao emitir os títulos de dívida (BRASIL, 2020b).

As medidas descritas nos parágrafos anteriores, assim como os dados levantados, apontam para uma crescente importância do mercado de títulos corporativos como canal de financiamento à infraestrutura no país. Além do crescimento deste canal, entretanto, parece estar em curso um acirrado processo de desmonte dos canais públicos de financiamento (sobre os quais erige-se o padrão tradicional de financiamento de longo prazo no país). São estes dois processos distintos, mas convergentes no efeito de alterar as bases do financiamento de longo prazo no país, que nos permitem aqui falar de mudanças no padrão de financiamento à infraestrutura no Brasil.

\section{A MUDANÇA NO PADRÃO DE FINANCIAMENTO}

As diferentes formas de financiamento ao investimento em infraestrutura em um país não são, e não deveriam ser, excludentes entre si. Neste sentido, o desenvolvimento de um mercado interno de capitais robusto, bem articulado e capaz de financiar a longo prazo poderia aliviar as pressões por financiamento sobre bancos públicos, reservando a estes funções estratégicas. Conforme sustentou Costa (2015, p. 40-41), a "miscigenação da economia de endividamento com a economia de mercado de capitais" poderia fornecer condições para estabelecer "um circuito virtuoso, acelerando a geração de fontes de financiamento em longo prazo para a construção de infraestrutura e logística do Estado de bem-estar social".

\footnotetext{
${ }^{6}$ Para zero, no caso de pessoas físicas, e $15 \%$ no caso de pessoas jurídicas, tais como fundos de investimento.
} 
Para tanto, a participação ativa do Estado seria imprescindível no lançamento das bases e condições para o estabelecimento deste "circuito virtuoso" de ampliação das fontes de financiamento em longo prazo. Entretanto, em vez desta visão de corte "liberal-desenvolvimentista" (TORRES FILHO; COSTA, 2013, p. 43), parece estar predominando uma abordagem neoliberal ortodoxa, que deposita uma fé cega nos mecanismos de mercado.

O mercado de capitais como fonte viável de financiamento não tem se somado ao financiamento a partir de crédito bancário público. Pelo contrário: o BNDES tem sido esvaziado nos anos recentes aparentemente sob justificativa de que o mercado privado (de crédito ou de capitais) autonomamente daria conta de suprir as demandas por recursos. Esta concepção (e prática em curso) parece ecoar as velhas abordagens neoliberais ao BNDES, segundo a qual o mercado privado não se desenvolveu por causa do Banco, quando há elementos que asseguram que historicamente o BNDES cumpriu a providencial função de justamente suprir as lacunas deixadas por um mercado privado incapaz de assegurar o financiamento de que o Brasil demandou e demanda (TORRES FILHO; COSTA, 2012).

Citando de passagem alguns meios pelos quais o BNDES tem sido enfraquecido: substituição da TJLP (Taxa de Juros de Longo Prazo) pela TLP (Taxa de Longo Prazo) como custo de referência do Banco (TORRES FILHO, 2017; PEREIRA, MITERHOF, 2018) ${ }^{7}$; maciça venda de ativos da carteira do BNDESPar (FILGUEIRAS, 2019); proposta de extinção do Fundo PIS-Pasep e transferência de seu patrimônio ao FGTS (AFBNDES, 2020).

Assim, alijar o Banco da função que providencialmente tem cumprido ao longo de setenta anos, sem a certeza de que há um mercado privado capaz de substituí-lo, parece mais profissão de fé do que uma ação concreta no sentido de fortalecer o mercado privado de crédito: parece haver uma crença de que apenas o esvaziamento do Banco automaticamente criaria uma oferta privada capaz de cumprir sua função, o que não parece ser o caso.

Vale dizer, ainda, que há uma série de políticas e mecanismos de estímulo ao desenvolvimento do mercado interno de capitais que poderiam ser gradualmente implementados sem passar pelo desmonte do BNDES. Neste sentido, prioritária seria a atenuação do perfil curto-prazista dos fundos de investimento e demais agentes financeiros no país. Há também, conforme destaca Ferreira (2017, p. 40), a "cultura do CDI": "essa convenção de que as aplicações financeiras devam render no mínimo o que rende o Certificado de Depósito Interbancário (CDI) é o benchmark com o qual os donos da riqueza se acostumaram e os tomadores de decisão trabalham no mercado".

Ainda a mesma autora, em interessante estudo sobre o comportamento dos fundos financeiros de 2003 a 2015, corrobora a percepção de que a alocação dos investimentos por parte dos fundos depende muito das expectativas do movimento da taxa básica de juros, confirmando a existência de "uma importante interface entre o perfil de emissão do Tesouro e o apetite dos fundos" (FERREIRA, 2017, p. 40). Neste mesmo sentido, como colocam Wolf, Oliveira e Palludeto (2018, p. 166):

\footnotetext{
${ }^{7}$ A taxa extinta (TJLP) era "flutuante e administrada, vigente ao longo da vida dos projetos, definida pelo Conselho Monetário Nacional (CMN) em patamar em geral inferior às taxas de mercado" (PEREIRA; MITERHOF, 2018, p. 878). A taxa substituta (TLP) deve acompanhar a NTN-B (Nota do Tesouro Nacional - Série B) de cinco anos, título indexado ao IPCA que sobre a variação deste índice acresce uma taxa de juros fixa. Para Torres Filho (2017, p. 9), "o pior efeito da nova taxa será impor um custo de captação extremamente elevado, que simplesmente tornará o BNDES o banco de desenvolvimento que empresta às taxas mais altas do mundo".
} 
os títulos de dívida pública são substitutos, em vez de complementares, aos demais segmentos do mercado de capitais no Brasil. Por ter risco de crédito praticamente nulo, eles deveriam oferecer uma referência para rendimento e prazo para todos os demais ativos negociados nesse mercado. Ocorre, contudo, que sob a égide da institucionalidade financeira e da existência de diversos indexadores dos títulos públicos, além dos papeis prefixados, esses ativos apresentam retorno elevado, alta liquidez e prazos médios efetivos curtos, rompendo-se com o trade-off liquidez $x$ rentabilidade.

Assim, o atual cenário de Selic baixa pode impelir investidores a assumir risco e diversificar alocações em busca de compensar a rentabilidade de outrora. Entretanto, eventual alta na taxa básica de juros pode fazer o cenário mudar. Isso porque, como colocado por Oliveira, Cioffi e Conti (2017, p. 33):

as condições em que as debêntures são emitidas são muito condicionadas pela Dívida Pública Mobiliária Federal (DPMF), que funciona como um benchmark para a formação de preços e estabelecimento de prazos de maturação na sua contraparte privada: além da influência exercida pelo patamar da Selic e os prazos de vencimento da DMPF, a estrutura de indexação da dívida mobiliária federal também contribui para as condições prevalecentes no mercado privado.

Da mesma forma, o prenúncio de uma crise mais acentuada pode fazer secar os investimentos em debêntures de infraestrutura tendo em vista a preferência dos agentes pela liquidez. Se se abre mão (como tem acontecido) de um instrumento potencialmente contracíclico como o BNDES, corre-se se o risco de depender de agentes altamente instáveis e de mobilidade virtualmente ilimitada. A situação se agrava tendo em vista certos vícios de um mercado de capitais curto-prazista, atavicamente avesso ao risco e acostumado ao generoso "piso" para rentabilidade das aplicações que é o CDI. Neste sentido "é imperativo que a composição da poupança financeira doméstica evolua progressivamente no sentido de uma menor preferência pela liquidez e maior exposição aos mercados de ações e ativos alternativos vinculados à atividade produtiva" (OLIVEIRA; CIOFFI; CONTI, 2017, p. 39). Seriam necessários também estímulos para a consolidação de um mercado secundário maduro que possa conferir liquidez aos títulos corporativos (TORRES FILHO; MACAHYBA, 2012).

Assim, conclui-se que há ainda um longo caminho para constituição de um mercado de capitais robusto e capaz de suprir autonomamente as demandas de investimentos de longo prazo. Disso infere-se a persistência da importância de um Banco de Desenvolvimento (BD). Isto posto, a assunção de maior protagonismo por parte dos agentes financeiros no financiamento à infraestrutura via debêntures não deveria eliminar o BNDES; antes, um padrão virtuoso de desenvolvimento e melhoria da infraestrutura nacional passa pela equalização adequada das funções de ambos, agentes públicos e privados (COSTA, 2015).

Ademais, que agentes ou instituições, senão públicas/estatais - cuja premissa pode ser outra além da acumulação de capital -, para financiar ou empreender investimentos de início pouco rentáveis, mas prenhes de externalidades positivas? É esta também uma função precípua e fundamental dos bancos de investimento públicos: investir em setores novos nos quais os mercados privados não estão dispostos a apostar. Mazzucato (2014), ao tratar sobre este tema e ressaltar a 
importância desta participação, muitas vezes ocultada, do Estado nas inovações tecnológicas, cita inclusive o BNDES como caso exemplar deste tipo de atuação positiva.

\section{CONSIDERAÇÕES FINAIS}

Por fim, vale frisar que nossa preocupação com este novo padrão de financiamento à infraestrutura que têm se desenhado nos últimos anos no país é quanto ao abandono do financiamento público, representado principalmente pela reorientação e esvaziamento do BNDES. Deve ter ficado claro ao leitor que não guardamos oposição quanto à tentativa de estímulo ao mercado de capitais em sua capacidade de financiar no longo prazo. Como foi dito, o amadurecimento do setor financeiro privado neste sentido poderia ajudar na provisão de crédito de que o país demanda para enfrentar o hiato em sua infraestrutura territorial. Entretanto, o estímulo ao setor privado não deveria pressupor implosão dos meios de financiamento estatal, ao qual poderia se acoplar sem destruir.

Entendemos que, se não se quer que as obras de infraestrutura (mormente via concessões) sejam plataforma para ganhos financeiros (infraestrutura para a finança), e sim que o financiamento esteja à serviço das obras planejadas (financiamento para infraestrutura), demanda-se uma reorientação do papel Estado em busca de uma inserção ativa no atual quadro de possibilidades de financiamento. Emprestamos aqui uma reflexão colocada por Milton Santos (2008, p. 114) que representa bem a questão colocada:

Tudo está a indicar que o subsistema do mercado se sobrepõe ao subsistema governamental em diversos domínios, inclusive o da organização do espaço (...). O problema é, então, o de saber como a situação poderia ser invertida, ou como o subsistema governamental poderia atuar de forma a obter os meios eficazes à realização dos fins que se pretende.

Conforme apresentado neste trabalho, parece estar havendo, ao contrário, a reafirmação de uma inserção passiva na financeirização (PAULANI, 2013). Com Arroyo (2006), talvez possamos pensar nos termos de uma ampliação da vulnerabilidade do território brasileiro frente às finanças. Este suposto novo padrão de financiamento à infraestrutura poderá ser mobilizado de modo a viabilizar os projetos de que o Brasil demanda? Ou o planejamento estaria cada vez mais condicionado aos interesses particulares do capital que se valoriza na esfera financeira?

Conforme foi brevemente apresentado (e referimo-nos aqui principalmente ao desmonte do BNDES, sobre o que pretendemos tratar melhor em outra ocasião) parece estar em curso um acirramento do movimento de perda da capacidade de planejamento do Estado (BRANDÃO, 2011) e sua transferência direta aos agentes econômicos hegemônicos (SILVEIRA, 2009). Estes passam a impor sua lógica corporativa como princípio ordenador do planejamento e insturando novos usos do território, mais corporativos e predatórios (SANTOS, 1997).

Neste sentido, entendemos que estes reflexos da financeirização por sobre a infraestrutura territorial pública dá prosseguimento e acirra este movimento de diminuição da participação direta do Estado no segmento. Seria a intensificação dos processos iniciados em fins do século passado no país, marcados pela "saída do Estado de uma série de setores por meio de privatizações e concessões de serviços públicos a particulares" (ANTAS JR., 2005, p. 205). 
Ou seja: se a estrutura de financiamento de longo prazo no país seguir no rumo indicado pelas transformações atualmente em curso e suscintamente descritas ao longo deste trabalho, o país passará a depender cada vez mais de agentes financeiros privados para custear a renovação das materialidades de que demanda o território brasileiro, reiterando uma inserção passiva no contexto da financeirização. Entendemos, assim, que se trata de um aprofundamento da lógica privatista de uso do território. O financiamento dos projetos em infraestrutura, na medida em que se torna cada vez mais dependente dos desígnios de agentes privados (altamente voláteis, vale frisar), tem potencial para aprofundar ainda mais a seletividade do processo de renovação das materialidades do território brasileiro. ${ }^{8}$

\section{REFERÊNCIAS}

AFBNDES. ASSOCIAÇÃO DOS FUNCIONÁRIOS DO BNDES. Na contramão do que anseia o governo, emenda à MP 946 tenta manter relevância do BNDES no combate à crise. Disponível em: http://www.afbndes.org.br/extramp946.htm. Acesso em: 08 set. 2020 .

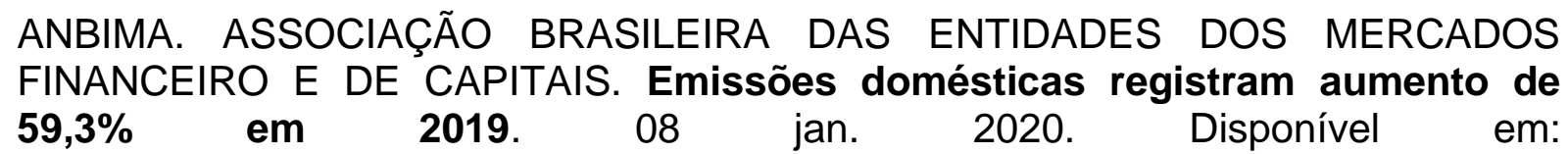
https://www.anbima.com.br/pt_br/informar/relatorios/mercado-de-capitais/boletim-demercado-de-capitais/emissoes-domesticas-registram-aumento-de-59-3-em-

2019.htm\#: :text=As\%20emiss\%C3\%B5es\%20de\%20deb\%C3\%AAntures\%20manti veram,m\%C3\%A9dio\%20de\%20coloca\%C3\%A7\%C3\%A3o\%2C\%20de\%205.

Acesso em: 29 jan. 2021.

ANTAS JR., R. M. Território e regulação: espaço geográfico, fonte material e nãoformal do direito. São Paulo: Humanitas, 2005

ARROYO, M. A vulnerabilidade dos territórios nacionais latino-americanos: o papel das finanças. In: LEMOS, A. I. G. de; SILVEIRA, M. L.; ARROYO, M. (Orgs.). Questões territoriais na América Latina. Buenos Aires: Ed. Clacso, 2006.

BELLUZZO, L. G. O capital e suas metamorfoses. São Paulo: Editora Unesp, 2013.

BRAGA, J. C. de S. Financeirização global - O padrão sistêmico de riqueza do capitalismo contemporâneo. In: TAVARES, M. da C.; FIORI, J. L. (Orgs.). Poder e Dinheiro: uma economia política da globalização. Rio de Janeiro: Vozes, 1997. p. 195-242.

BRANDÃO, C. A. A Busca da Utopia do Planejamento Regional. Revista Paranaense de Desenvolvimento, Curitiba, n. 120, p. 17-37, jan. 2011.

BRASIL. Lei no 8.987, de 13 de fevereiro de 1995: Dispõe sobre o regime de concessão e permissão da prestação de serviços públicos previsto no art. 175 da Constituição Federal, e dá outras providências. Brasília: 1995. Disponível em:

\footnotetext{
${ }^{8}$ Agradeço à Fundação de Amparo à Pesquisa do Estado de São Paulo - FAPESP pela concessão de bolsa de pesquisa (n 2019/26491-7) em cujo âmbito foi desenvolvido o presente trabalho.
} 
http://www.planalto.gov.br/ccivil_03/leis/L8987compilada.htm. Acesso em: 30 set. 2020

BRASIL. Proposta cria novo tipo de debênture para investimento em infraestrutura. Agência Câmara de Notícias (Online), 02 jun. 2020 (2020b). Disponível em: https://www.camara.leg.br/noticias/666202-proposta-cria-novo-tipo-de-debenturepara-investimento-eminfraestrutura/\#: :text=O\%20Projeto\%20de\%20Lei\%202646,PD\%26I)\%20considera dos\%20priorit\%C3\%A1rios\%20pelo\%20governo. Acesso em: 30 set. 2020.

CASTRO, A.; LESSA, C. Introdução à economia: uma abordagem estruturalista. Rio de Janeiro: Forense Universitária, 1973.

CHESNAIS, F. A proeminência da finança no seio do "capital em geral", o capital fictício e o movimento contemporâneo de mundialização do capital. In: BRUNHOFF, S. de. et al. (Orgs.). A finança capitalista. São Paulo: Alameda, 2010. p. 95-182.

CHESNAIS, F. O capital portador de juros: acumulação, internacionalização, efeitos econômicos e políticos. In: CHESNAIS, F. (Org.). A finança mundializada: raízes sociais e políticas, configuração, consequências. São Paulo: Boitempo, 2005.

COSTA, F. N. da. Financiamento interno de longo prazo. Brasília: Ipea, 2015. (Texto para discussão n. 2053).

COSTA, B. M. R.; GALLO, F. Concessão rodoviária como plataforma de valorização financeira: expressão do uso corporativo do território. Terra Livre, v. 1, n. 54, p. 321361, jan.-jun./2020.

COUTINHO, L. G.; BELLUZZO, L. G. M. Desenvolvimento e estabilização sob finanças globalizadas. Economia e Sociedade (Campinas), v. 7, n. 1, p. 129-154, dez. 1996.

CVM. COMISSÃO DE VALORES MOBILIÁRIOS. O mercado de dívida corporativa no Brasil. Comissão de Valores Mobiliários, 2018. Disponível em: http://www.cvm.gov.br/export/sites/cvm/menu/acesso_informacao/serieshistoricas/es tudos/anexos/estudo_cvm_mercado_de_divida_corporativa_no_Brasil.pdf. Acesso em: 08 nov. 2020.

CVM. COMISSÃO DE VALORES MOBILIÁRIOS. O mercado de valores mobiliários brasileiro. 3. ed. Rio de Janeiro: Comissão de Valores Mobiliários, 2014. 376p

FERREIRA, A. N. Fundos de investimentos de 2003 a 2015: proxy de lucro e análise da composição da carteira por segmento de investidor, classe de fundos e categoria de ativos. Brasília: Ipea, 2017. (Texto para discussão n. 2332).

FERREIRA, A. N. Os fundos de investimento no Brasil de 2008 a 2013: institucionalidade e interfaces com a política econômica. Brasília: Ipea, 2015. (Texto para discussão n. 2153).

FILGUEIRAS, M. L. BNDES deve vender $\mathrm{R} \$ 35$ bi em ativos até fim do ano. Valor Econômico (online) 29 jul. 2019. Disponível em: 
https://valor.globo.com/financas/noticia/2019/07/29/bndes-deve-vender-r-35-bi-emativos-ate-fim-do-ano.ghtml. Acesso em: 08 set. 2020

HARVEY, D. Os limites do capital. São Paulo: Boitempo, 2013.

MARX, K. O Capital: crítica da economia política. Livro 1: O processo de produção do capital. São Paulo: Boitempo, 2013.

MARX, K. O Capital: crítica da economia política. Livro Segundo: O processo de circulação do capital. São Paulo: Nova Cultural, 1985.

MARX, K. O Capital: crítica da economia política. Livro Terceiro: O processo global da produção capitalista. Tomo 1 (Parte Primeira). São Paulo: Nova Cultural, 1986.

MAZZUCATO, M. O estado empreendedor: desmascarando o mito do setor público vs. setor privado. São Paulo: Portfolio-Penguin, 2018.

OLIVEIRA, G. C. de; CIOFFI, F.; CONTI, B. de. Os Fundos de pensão e o financiamento de longo prazo no Brasil: possibilidades e limites. Revista Pesquisa \& Debate, São Paulo, vol. 28, n. 1 (51), jul 2017. p. 15-41.

PALLUDETO, A. W. A.; ROSSI, P. O capital fictício: revisitando uma categoria controversa. Texto para Discussão (Unicamp - Instituto de Economia), n. 347, ago. 2018.

PAULANI, L. Acumulação Sistêmica, Poupança Externa e Rentismo: observações sobre o caso brasileiro. Estudos Avançados, São Paulo, IEA/USP, v. 27, n. 77, 2013.

PEREIRA, T. R.; MITERHOF, M. T. O Papel do BNDES e o financiamento do desenvolvimento: considerações sobre a antecipação dos empréstimos do tesouro nacional e a criação da TLP. Economia e Sociedade, Campinas, v. 27, n. 3, p. 875908, dez. 2018.

SANTOS, M. Da política dos Estados à política das empresas. Cadernos da Escola do Legislativo. Belo Horizonte, v. 3, n. 6, p. 3-191, jul./dez. 1997.

SANTOS, M. Espaço e Método. São Paulo: EDUSP, 2008. (Coleção Milton Santos; 12).

SILVEIRA, M. L. Ao território usado a palavra: pensando princípios de solidariedade socioespacial. In VIANA, A. L. A.; IBAÑEZ, N.; ELIAS, P. E. M. (Org.). Saúde, desenvolvimento e território. São Paulo: Aderaldo \& Rotschild, 2009.

SINGER, P. Para entender o mundo financeiro. São Paulo: Editora Contexto, 2000.

TAUHATA, S Empresas brasileiras captaram R $\$ 498,2$ bilhões em 2019, diz Anbima. Valor Econômico (online), 08 jan. 2020. Disponível em: https://valor.globo.com/financas/noticia/2020/01/08/empresas-brasileiras-captaram-r4982-bilhoes-em-2019-diz-anbima.ghtml. Acesso em: 23 set. 2020. (2020a)

TAUHATA, S. Gestores veem mais FIP de infraestrutura na bolsa. Valor Econômico (online),

15 jul.

2020.

Disponível

em: 
https://valor.globo.com/financas/noticia/2020/07/15/gestores-veem-mais-fip-deinfraestrutura-na-bolsa.ghtml. Acesso em: 23 set. 2020. (2020b)

TAVARES, M. da C. O sistema financeiro brasileiro e o ciclo de expansão recente. In: BELLUZZO, L. G. M.; COUTINHO, R. Desenvolvimento capitalista no Brasil: ensaios sobre a crise. São Paulo: Brasiliense, 1983. v. 2, p. 107-138.

TORRES FILHO, E. T. A extinção da TJLP dá início ao projeto de desmonte do BNDES. Jornal dos Economistas: Rio de Janeiro, jun. 2017.

TORRES FILHO, E. T.; COSTA, F. N. da. Financiamento de longo prazo no Brasil: um mercado em transformação. Brasília: Ipea, 2013. (Texto para discussão $n .1843$ ).

TORRES FILHO, E. T.; MACAHYBA, L. O elo perdido: o mercado de títulos de dívida corporativa no Brasil - avaliação e propostas. São Paulo: IEDI; Instituto Talento Brasil, jun. 2012. Disponível em: http://goo.gl/w818Ar. Acesso em: 08 set. 2020. 